\title{
Influence of Oxygenated Compounds on Reaction Products in a Microwave Plasma Methane Pyrolysis Assembly for Post-Processing of Sabatier Methane
}

\author{
J. Matthew Mansell $^{1}$ and Morgan B. Abney. ${ }^{2}$ \\ NASA Marshall Space Flight Center, Huntsville, AL, 35812 \\ and \\ Lee A. Miller ${ }^{3}$ \\ ECLS Technologies, LLC., Huntsville, AL, 35802
}

\begin{abstract}
The state-of-the-art Carbon Dioxide Reduction Assembly (CRA) was delivered to the International Space Station (ISS) in April 2010. The system is designed to accept carbon dioxide from the Carbon Dioxide Removal Assembly and hydrogen from the Oxygen Generation Assembly. The two gases are reacted in the CRA in a Sabatier reactor to produce water and methane. Venting of methane results in an oxygen resupply requirement of about $378 \mathrm{lbs}$ per crew member per year. If the oxygen is supplied as water, the total weight for resupply is about $476 \mathrm{lb}$ per crew member per year. For long-term missions beyond low Earth orbit, during which resupply capabilities will be further limited, recovery of hydrogen from methane is highly desirable. For this purpose, NASA is pursuing development of a Plasma Pyrolysis Assembly (PPA) capable of recovering hydrogen from methane. Under certain conditions, water vapor and carbon dioxide (nominally intended to be separated from the CRA outlet stream) may be present in the PPA feed stream. Thus, testing was conducted in 2010 to determine the effect of these "oxygenated" compounds on PPA performance, particularly the effect of inlet carbon dioxide and water variations on the PPA product stream. This paper discusses the test set-up, analysis, and results of this testing.
\end{abstract}

\section{Nomenclature}

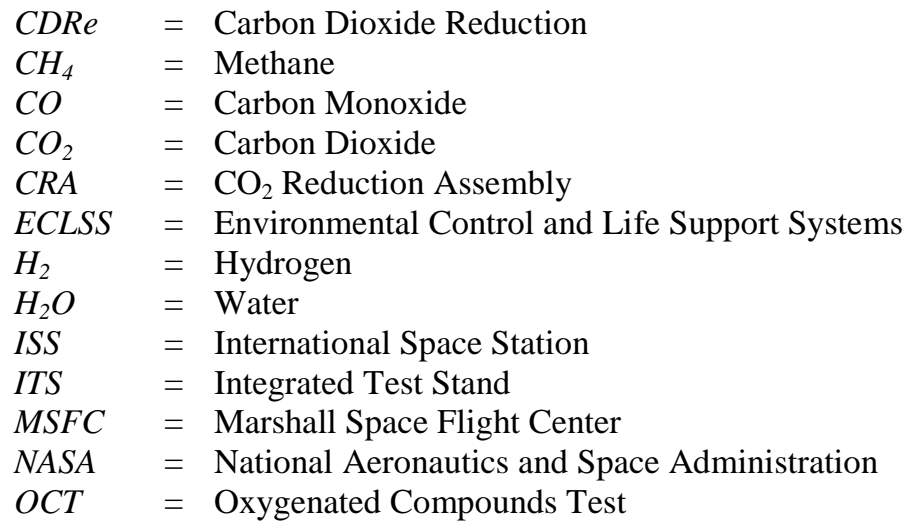

\footnotetext{
1 Test Engineer, Environmental Control and Life Support Systems Development Branch, Bldg 4755 Room 115, Huntsville, AL, AIAA member.

${ }^{2}$ Aerospace Engineer, Environmental Control and Life Support Systems Development Branch, Bldg 4755 Room 403-7, Huntsville, AL 35812, AIAA Member.

3 Test Engineer, Environmental Control and Life Support Systems Development Branch, Bldg 4755 Room 103A, Huntsville, AL 35812, AIAA Senior Member.
} 
$O G S \quad=$ Oxygen Generation System

$P P A=$ Microwave Plasma Pyrolysis Assembly

$S C C M=$ Standard Cubic Centimeters per Minute

$S D U=$ Sabatier Development Unit

\section{Introduction}

single human being exhales approximately $1 \mathrm{~kg}$ of carbon dioxide $\left(\mathrm{CO}_{2}\right)$ per day. Prior to 2010, state-of-the-art A technology was able to remove $\mathrm{CO}_{2}$ from spacecraft cabin air, before storing or venting overboard. The expense of replacing the mass - particularly oxygen -is undesirable but manageable for operations in low Earth orbit (LEO) such as the International Space Station (ISS). However, the multiplied cost of delivering that mass to destinations beyond LEO for long-term exploration missions could be a critical limitation on the missions' distance from Earth and duration, as well as payload available for redundant safety systems, scientific equipment, and other applications. Carbon Dioxide Reduction (CDRe) systems greatly reduce oxygen supply requirements by converting the oxygen bound in $\mathrm{CO}_{2}$ into water or molecular oxygen. To that end, Environmental Control and Life Support Systems (ECLSS) groups at several NASA centers, as well as commercial and academic partner sites, are developing a number of CDRe technologies. On April 5, 2010, the $\mathrm{CO}_{2}$ Reduction Assembly (CRA), developed and built by Hamilton Sundstrand, was delivered to the ISS by STS-131. The CRA is based on the Sabatier process, which proceeds by the following overall reaction:

$$
\mathrm{CO}_{2}+4 \mathrm{H}_{2} \rightarrow \mathrm{CH}_{4}+2 \mathrm{H}_{2} \mathrm{O}
$$

The recovered water can be electrolyzed in an Oxygen Generation System (OGS) to form molecular oxygen to support the crew and hydrogen for further $\mathrm{CO}_{2}$ reduction. When the CRA is operated on ISS, the methane will be vented overboard. The hydrogen bound in the vented methane must be replaced in order to continue the process. Currently, MSFC ECLSS is investigating the Microwave Plasma Pyrolysis Assembly (PPA) as a means to recover a portion of that hydrogen. The PPA was built by the UMPQUA Research Company and delivered to MSFC in May 2009 as part of a Small Business Innovative Research (SBIR) Phase II contract. The primary reaction of the PPA is as follows:

$$
2 \mathrm{CH}_{4} \rightarrow \mathrm{C}_{2} \mathrm{H}_{2}+3 \mathrm{H}_{2}
$$

The PPA utilizes microwaves to generate a hydrogen plasma in which the methane reacts to form acetylene and hydrogen. Including a pyrolysis reactor downstream of a Sabatier system increases theoretical hydrogen recovery from $50 \%$ to $87.5 \%$, and overall mass recovery from $69.2 \%$ to $75 \%$, per cycle. However, a number of side reactions have the potential to occur in the plasma:

$$
\begin{aligned}
\mathrm{CH}_{4} & \rightarrow \mathrm{C}(\mathrm{s})+2 \mathrm{H}_{2} \\
2 \mathrm{CH}_{4} & \rightarrow \mathrm{C}_{2} \mathrm{H}_{4}+2 \mathrm{H}_{2} \\
2 \mathrm{CH}_{4} & \rightarrow \mathrm{C}_{2} \mathrm{H}_{6}+\mathrm{H}_{2}
\end{aligned}
$$

Considerable testing has already been conducted on the PPA, and results of those tests have been reported. ${ }^{1-2}$ Previous testing involved both stand-alone operation of the PPA and operation of a Sabatier-PPA integrated test stand (ITS). In each of those tests, $\mathrm{CO}_{2}$ and water in the PPA feed stream were limited to trace levels. Both of those compounds may be present in a Sabatier outlet stream: unreacted $\mathrm{CO}_{2}$ due to incomplete conversion in the Sabatier, and water if the Sabatier outlet is not fully dehumidified. Carbon dioxide has been shown to disassociate to form oxygen and carbon monoxide in plasmas. ${ }^{3}$ Similarly, water has been shown in many sources to disassociate to form oxygen and hydrogen in plasmas. Therefore, it is theoretically possible to have a mixture in the PPA containing some level of oxygen. Since the system contains large fractions of high flammable fuel gases (hydrogen, methane, acetylene, etc), the production of oxygen (or any other oxidizers) is clearly a safety concern. Thus, the objective of the PPA Oxygenated Compounds Test (OCT) was to determine the effects of $\mathrm{CO}_{2}$ and water on PPA performance, especially product stream composition. To ensure complete understanding, nominal and off-nominal Sabatier Development Unit (SDU) product streams were generated for testing. This paper provides an overview of testing hardware, procedures, analysis and results of the Oxygenated Compounds Test. 


\section{Hardware Description}

The equipment utilized for this test included the Sabatier Development Unit (SDU), the Microwave Plasma Pyrolysis Assembly (PPA), and an integration panel.

\section{A. Sabatier Development Unit}

The SDU hardware was developed and refurbished by Hamilton Sundstrand between fiscal years 2008 and 2009. A housing encloses the Sabatier reactor and a condensing heat exchanger along with an assortment of valves, regulators, pumps, heaters, and instrumentation. The SDU is controlled with a Lookout Direct (National Instruments) application running on an external computer. Data collection and recording is accomplished with a NASA-developed program called PACRATS.

\section{B. Microwave Methane Pyrolysis}

The PPA hardware was developed by UMPQUA Research Company under an SBIR Phase II grant and delivered to MSFC ECLSS in FY09. The primary components of the PPA are a vacuum pump, magnetron (the microwave source), microwave tuner, reactor chamber, filter, and chiller. The system can be controlled locally or remotely per the requirements of the testing.

Several feed ports are present in the reactor. The SDU product gas, after passing through the integration panel, enters the PPA reactor through the "main" feed port in-line with the center of the reactor. Pure hydrogen is fed to the reactor through three "sweep" ports, the purpose of which is to prevent carbon deposition on the internal surfaces of the reactor. The hydrogen flow rates through the three sweep ports are independently controllable.

\section{Integration Panel}

The integration panel houses a number of components that facilitate connection of the SDU and PPA. These components include a group of valves, pressure controllers, and mass flow controllers that allow the SDU outlet stream to be split, with most of the gas flowing through a vent line to exit the building, and the remainder feeding the PPA. Downstream of these valves are a sorbent bed with proportional bypass control and a $\mathrm{CO}_{2}$ mass flow controller, which together allow control of the water vapor and $\mathrm{CO}_{2}$ concentrations in the stream. A schematic of the integrated test stand is shown in Figure 1.

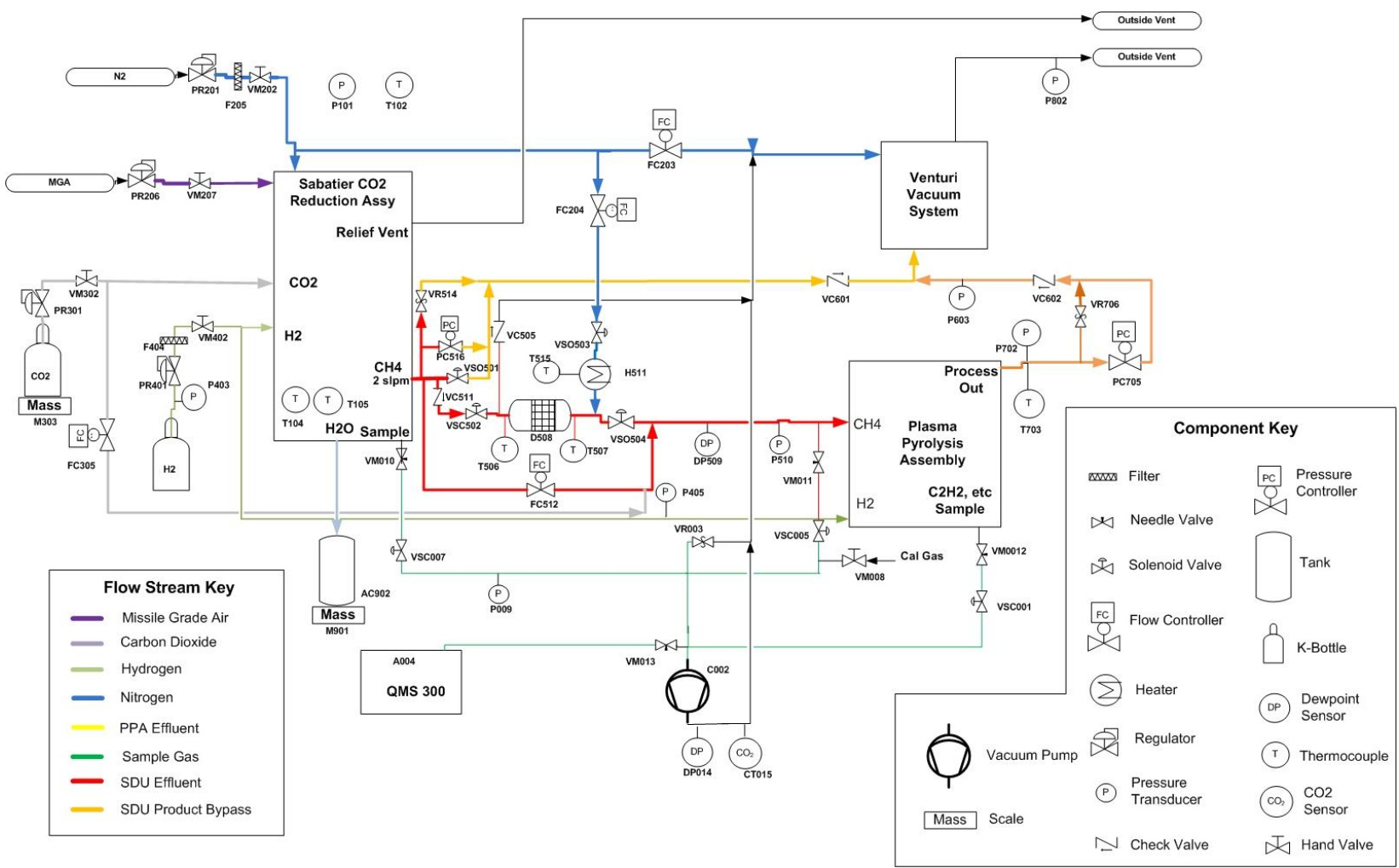

Figure 1. Schematic of Sabatier Development Unit/Microwave Plasma Pyrolysis Assembly Integration Hardware. 


\section{Methods}

In order to evaluate the effects of oxygenated compounds on PPA operation, a test plan consisting of 24 trials was prepared. It was determined that the safest and most feasible means to produce the desired PPA feed stream compositions was to operate the Sabatier Development Unit (SDU) in an integrated configuration with the Microwave Plasma Pyrolysis Assembly (PPA) and adjust the water and $\mathrm{CO}_{2}$ fractions in the PPA feed stream, rather than utilize pure or pre-mixed methane, hydrogen, $\mathrm{CO}_{2}$, and water vapor sources. Through all trials, the compositions of the reactant and product streams were monitored by mass spectroscopy. The trials were divided into two series, with the first 19 trials forming Series A and the last five trials forming Series B. Samples were regularly taken for analysis by gas chromatography to confirm the accuracy of the spectroscopic composition measurements. Details of each series of testing are provided below.

\section{A. Series A Methods}

Series A was conducted in order to gather data for the direct characterization of the effects of $\mathrm{CO}_{2}$ and water vapor in greater-than-trace amounts on performance of the PPA. Performance was characterized by the overall conversion of methane and selectivity for production of acetylene over $\mathrm{CO}$, as well as by hydrogen recovery, $\mathrm{H}_{2}$ versus $\mathrm{H}_{2} \mathrm{O}$ selectivity, and various efficiencies.

In Series A, the SDU was operated with the intent of producing a consistent SDU outlet stream composition. The majority of that stream was vented, while the remaining portion formed a "base" stream for the PPA reactant gas feed. Using the instrumentation described in the previous section, water was removed from, and $\mathrm{CO}_{2}$ added to, the base stream in varying amounts to produce the desired PPA feed stream compositions. The test variables for this series were the flow rates of $\mathrm{CO}_{2}$ and $\mathrm{H}_{2} \mathrm{O}$ through the PPA main feed port. The control variables included the methane and hydrogen flow rates through the PPA main feed port, flow rates through the three hydrogen sweep ports, microwave power, and reactor pressure. Each trial was conducted once.

\section{B. Series B Methods}

The final five trials were included for the purpose of evaluating PPA operation with varying SDU inlet stream compositions (and resulting product stream compositions) and no $\mathrm{CO}_{2}$ injection nor water removal between the SDU and PPA. This provided inlet stream compositions to which the PPA could potentially be exposed in a system configuration lacking water/ $\mathrm{CO}_{2}$ adsorption between the two subsystems. Whereas the objective of Series A was to relate PPA operation directly and solely to the $\mathrm{CO}_{2}$ and $\mathrm{H}_{2} \mathrm{O}$ in the inlet stream, the Series B objective was to vary a single SDU parameter $\left(\mathrm{H}_{2}: \mathrm{CO}_{2}\right.$ feed ratio) in a mission operation-like manner, producing a cascade of changes downstream of the SDU and evaluate the ultimate effects on PPA operation. Water vapor concentrations were still limited to dew points lower than the ambient temperature. In Series A, the $\mathrm{H}_{2}: \mathrm{CO}_{2}$ ratio in the SDU inlet was maintained at 4:1. Series B included 3.5:1, 4.5:1, 5:1, 5.5:1, and 6:1 ratios. Results of this test series could also be compared to those of previous testing in which the same feed ratios were utilized with complete $\mathrm{CO}_{2}$ and $\mathrm{H}_{2} \mathrm{O}$ removal upstream of the PPA. Each trial was conducted once ${ }^{5}$ with the exception of trials 6,11 , and 16 , which were not conducted because the water vapor fraction in the PPA feed stream could not be controlled to the low level required.

For Series B, the test variable was the SDU hydrogen feed rate. The control variables included the SDU $\mathrm{CO}_{2}$ feed rate, SDU reactor temperature and pressure, flow rate of methane in the PPA main feed stream, total PPA $\mathrm{H}_{2}$ feed rate (through the main port and the three sweep ports), PPA microwave power, and PPA reactor pressure.

\section{Analysis}

Analysis of the data collected during testing resulted in determination of reaction rates, $\mathrm{CO}_{2}$ conversion, hydrogen recovery, and the efficiency, selectivity, and yield of each product at each test point. The methods of analysis are described in detail below.

\section{A. Model Reactions}

In order to facilitate analysis, the system was described chemically by the following three simultaneous reactions:

Equation A:

Equation B:

Equation C:

$$
\begin{aligned}
2 \mathrm{CH}_{4} & \leftrightarrow \mathrm{C}_{2} \mathrm{H}_{2}+3 \mathrm{H}_{2} \\
\mathrm{CH}_{4}+\mathrm{CO}_{2} & \leftrightarrow 2 \mathrm{CO}+2 \mathrm{H}_{2} \\
\mathrm{CO}_{2}+\mathrm{H}_{2} & \leftrightarrow \mathrm{CO}+\mathrm{H}_{2} \mathrm{O}
\end{aligned}
$$

4

American Institute of Aeronautics and Astronautics 
No evidence is provided that Reactions $B$ and $C$ constitute the entirety of, or are actually components of, the true reaction mechanism. The mechanisms of this complex reaction system are not considered herein and are not of consequence to the analysis conducted for this paper. Any other reaction among the stable species involved can be described as a combination of these three reactions.

A number of basic reaction parameters were calculated to characterize the variations in PPA performance among the test trials. The rates of conversion or production of the six compounds involved in the reaction were calculated from equation 1:

$$
\text { (1) } \mathrm{n}_{\mathrm{i}}=\mathrm{n}_{\mathrm{out}, \mathrm{i}}-\mathrm{n}_{\mathrm{in}, \mathrm{i}} \text {, }
$$

Where $n_{\text {out, }}$ is the molar flow rate of compound $i$ at the outlet and $n_{i n, i}$ is the molar flow rate of component $i$ at the inlet. Rates of Reactions $A, B$, and $C$ were calculated from equations 2,3 , and 4 , respectively.

$$
\begin{gathered}
\text { (2) } r_{\mathrm{A}}=r_{\mathrm{C}_{2} \mathrm{H}_{2}} \\
\text { (3) } \mathrm{r}_{\mathrm{B}}=-\mathrm{r}_{\mathrm{CH}_{4}}-2 \mathrm{r}_{\mathrm{A}} \\
\text { (4) } \mathrm{r}_{\mathrm{C}}=\mathrm{r}_{\mathrm{H}_{2} \mathrm{O}}
\end{gathered}
$$

MATLAB's Surface Fitting Toolbox was used to determine empirical relationships describing the rate of each reaction as a function of the feed concentrations of $\mathrm{CO}_{2}$ and $\mathrm{H}_{2} \mathrm{O}$.

\section{B. Conversion and Hydrogen Recovery}

A number of conversion $(\chi)$ and recovery $(\tau)$ parameters were developed and calculated using the equations shown in Figure 2.

For conversions, $\chi_{\mathrm{CH}_{4}-\mathrm{j}}$ is the fraction of methane fed to the reactor which is converted to component $j \cdot \chi_{\mathrm{CH}_{4} \text {,total }}$ is the total fraction of methane which is converted to other compounds in the reactor. $\chi_{\mathrm{H}_{2} \text { (rec)- } \mathrm{H}_{2} \mathrm{O}}$ is the conversion of molecular hydrogen to water via Reaction $C$ (when Reaction $\mathrm{C}$ proceeds to the right) as a fraction of molecular hydrogen recovered from Reactions $A$ and $B . \chi_{\mathrm{CO}_{2}, \mathrm{~B}}$ is the fraction of $\mathrm{CO}_{2}$ fed to the PPA which is reduced to carbon monoxide (CO) via Reaction $B$. Likewise, $\chi_{\mathrm{CO}_{2}, \mathrm{C}}$ is the fraction of $\mathrm{CO}_{2}$ fed to the PPA which is reduced to $\mathrm{CO}$ via Reaction $C \cdot \chi_{\mathrm{CO}_{2} \text {,total }}$ is the fraction of $\mathrm{CO}_{2}$ fed to the PPA which is converted to all other compounds within the reactor.

For recovery, $\tau_{\mathrm{H}_{2}: \mathrm{CH}_{4}, \mathrm{x}}$ is the fraction of hydrogen bound in methane which is converted to molecular hydrogen via reaction $x$, including any portion of that hydrogen which is then converted to water through Reaction $C . \tau_{\mathrm{H}_{2}: \mathrm{CH}_{4} \text {,total }}$ is the total fraction of hydrogen bound in methane which is converted to molecular hydrogen. $\tau_{\mathrm{H}_{2}: \mathrm{H}_{2} \mathrm{O}}$ is the fraction of hydrogen bound in water which is recovered via Reaction $C$ (when Reaction $C$ proceeds to the left).

Graphical analysis using MATLAB's Surface Fitting Toolbox was conducted in order to determine simultaneously the effects of $\mathrm{CO}_{2}$ and $\mathrm{H}_{2} \mathrm{O}$ feed concentrations on methane and carbon dioxide conversions and hydrogen recovery.

$$
\begin{aligned}
& \text { (5) } \chi_{\mathrm{CH}_{4}-\mathrm{C}_{2} \mathrm{H}_{2}}=\frac{2 \mathrm{r}_{\mathrm{A}}}{\mathrm{n}_{\text {in, } \mathrm{CH}_{4}}} \\
& \text { (6) } \chi_{\mathrm{CH}_{4}-\mathrm{CO}}=\frac{\mathrm{r}_{\mathrm{CO}}+r_{\mathrm{CO}_{2}}}{\mathrm{n}_{i n, \mathrm{CH}_{4}}} \\
& \text { (7) } \chi_{\mathrm{CH}_{4}, \text { total }}=\chi_{\mathrm{CH}_{4}-\mathrm{C}_{2} \mathrm{H}_{2}}+\chi_{\mathrm{CH}_{4}-\mathrm{CO}} \\
& \text { (8) } \chi_{H_{2}(r e c)-H_{2} O}=\frac{r_{\mathrm{C}}}{3 r_{\mathrm{A}}+2 r_{B}} \\
& \text { (9) } \chi_{\mathrm{CO}_{2}, B}=\frac{\mathrm{r}_{\mathrm{B}}}{\mathrm{n}_{i n, \mathrm{CO}_{2}}} \\
& \text { (10) } \chi_{\mathrm{CO}_{2}, \mathrm{C}}=\frac{\mathrm{r}_{\mathrm{C}}}{\mathrm{n}_{\text {in, } \mathrm{CO}_{2}}} \\
& \text { (11) } \chi_{\mathrm{CO}_{2}, \text { total }}=\chi_{\mathrm{CO}_{2}, B}+\chi_{\mathrm{CO}_{2}, \mathrm{C}} \\
& \text { (12) } \tau_{\mathrm{H}_{2}: \mathrm{CH}_{4}, A}=\frac{3 r_{A}}{2 n_{i n, \mathrm{CH}_{4}}} \\
& \text { (13) } \tau_{\mathrm{H}_{2}: \mathrm{CH}_{4}, B}=\frac{2 r_{B}}{2 n_{i n, C H_{4}}} \\
& \text { (14) } \tau_{\mathrm{H}_{2}: \mathrm{CH}_{4}, \text { total }}=\tau_{\mathrm{H}_{2}, \mathrm{~A}}+\tau_{\mathrm{H}_{2}, \mathrm{~B}} \\
& \text { (15) } \tau_{\mathrm{H}_{2}: \mathrm{H}_{2} \mathrm{O}}=\frac{-r_{\mathrm{C}}}{n_{i n, \mathrm{H}_{2} \mathrm{O}}}
\end{aligned}
$$

Figure 2. Parameters and equations used for analysis of conversion $(\chi)$ and recovery $(\tau)$ data. 


\section{Efficiency, Selectivity, and Yield}

Several indicators of efficiency $(\eta)$, selectivity (S) and yield (Y) were derived with equations shown in Figure 3.

The subscript $i$ may denote parameters for reaction A, B, or C. Values for reaction rates are in given in sccm, and are therefore divided by 60 to put the denominator in the same per second basis as the numerator $(\mathrm{W}=\mathrm{J} / \mathrm{s})$. Microwave power was $700 \mathrm{~W}$ for all trials. Thus, $\eta_{\mathrm{A}}, \eta_{\mathrm{B}}$, and $\eta_{\mathrm{C}}$ are the fractions of microwave energy applied to the system which is consumed by reactions $\mathrm{A}$, $\mathrm{B}$, and $\mathrm{C}$, respectively, and therefore converted to the chemical potentials of the reaction products. Enthalpies of reaction, $\Delta \mathrm{H}_{\mathrm{A}}, \Delta \mathrm{H}_{\mathrm{B}}$, and $\Delta \mathrm{H}_{\mathrm{C}}$, were calculated from enthalpies of formation obtained from Perry's Chemical Engineers' Handbook $^{4}$ and are provided in Table 1. Selectivities of the form $\mathrm{S}_{\mathrm{A} / \mathrm{B}}$ indicate the favorability of one reaction product over another as moles of product $\mathrm{A}$ produced per moles of product B produced. Yields indicate the moles of each product produced per mole of methane consumed.

\section{Table 1. Reaction enthalpies for the PPA model} reactions.

\begin{tabular}{|c|c|c|c|}
\hline Reaction & A & B & C \\
\hline$\Delta \mathrm{H}_{\mathrm{i}}\left(\mathrm{J} / \mathrm{std} \mathrm{cm}^{3}\right)$ & 16.8411 & 11.0261 & 1.8376 \\
\hline
\end{tabular}

Graphical analysis using MATLAB's Surface Fitting Toolbox was conducted in order to determine simultaneously the effects of $\mathrm{CO}_{2}$ and $\mathrm{H}_{2} \mathrm{O}$ feed concentrations on PPA efficiencies, selectivities, and yields.

\section{Results and Discussion}

An iterative mass balance process was implemented by means of a custom MATLAB program to determine total quantities of components into and out of the system. Note that the complex nature of controlling the Integrated Test Stand (ITS) meant that the actual PPA reactant feed stream composition varied slightly from the desired composition.

\section{A. Series A Results and Discussion}

Series A test points were designed to stress the PPA performance by forcing high water and $\mathrm{CO}_{2}$ content into the PPA inlet stream. Results and Discussion of PPA performance under these conditions are provided below.

\section{Reaction Rates}

Rates for the three model reactions were plotted on three-dimensional axes against the $\mathrm{CO}_{2}$ and $\mathrm{H}_{2} \mathrm{O}$ feed stream mole fractions and fit with appropriate functions. 3-D graphs of the data points and resulting fits for the rate of reactions were generated. The resulting graph for Reaction $\mathrm{C}$ is shown in Figure 4 as an example. Statistical parameters for the fits of all reactions are provided in Table 2. All three reactions were best fit by polynomials of $1^{\text {st }}$

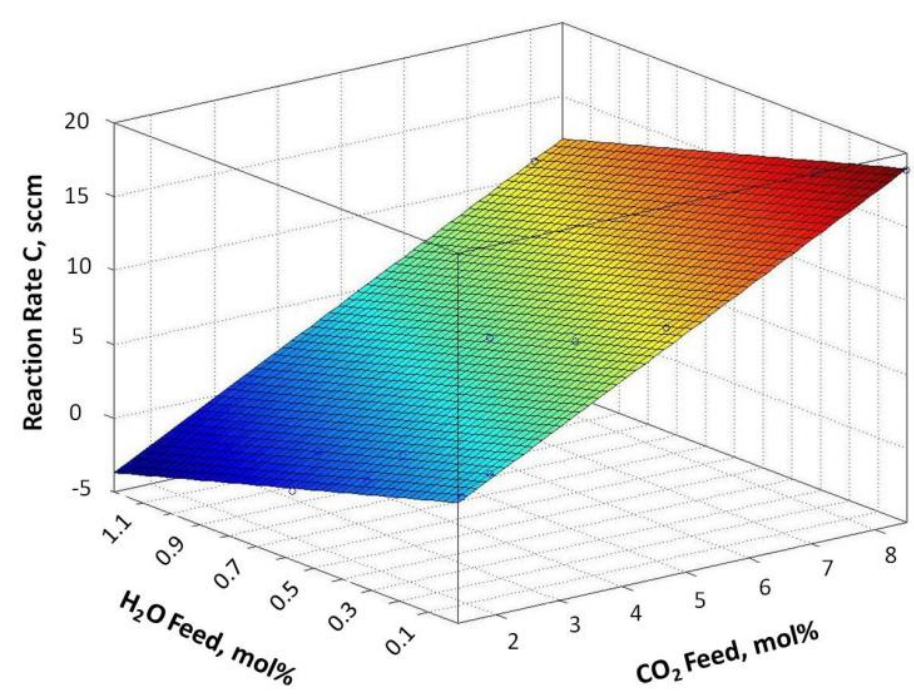

Figure 4. Rate of Reaction $\mathrm{C}$ (sccm) as a function of $\mathrm{CO}_{2}$ and $\mathrm{H}_{2} \mathrm{O}$ inlet stream mole fractions $(\%)$.

American Institute of Aeronautics and Astronautics 
Table 2. Series A reaction rate fit coefficients and coefficients of determination.

\begin{tabular}{|c|c|c|c|c|c|}
\hline Reaction & $\alpha$ & $\beta$ & $\delta$ & rsquare & adjusted rsquare \\
\hline A & 78.312 & -2.582 & -0.379 & 0.982 & 0.979 \\
\hline B & 0 & 6.027 & 3.160 & 0.975 & 0.974 \\
\hline C & 0 & 2.227 & -5.687 & 0.955 & 0.952 \\
\hline
\end{tabular}

order in both terms $\left(\mathrm{CO}_{2}\right.$ fraction and $\mathrm{H}_{2} \mathrm{O}$ fraction), which suggests that there is no significant coupling between the mechanisms of reaction of the two oxygenated compounds.

The three fit coefficients given in Table 2 describe the fit surface with the relationship:

$$
\mathrm{r}_{\mathrm{i}}(\mathrm{sccm})=\alpha+\beta^{*} \mathrm{y}_{\%, \mathrm{CO} 2}+\gamma^{*} \mathrm{y}_{\%, \mathrm{H} 2 \mathrm{O}}
$$

where $\mathrm{y} \%$, 's are mole fractions, in percent, of compound $\mathrm{j}$ in all feed streams (methane feed plus three hydrogen feed streams). The $\mathrm{R}^{2}$ values, each close to 1 , indicate that the model fits are reasonably accurate. The negative values of $\beta$ and $\gamma$ for the Reaction A fit confirm that both oxygenated compounds slow the rate of Reaction A. The positive values of $\beta$ and $\gamma$ for the Reaction B fit show that both oxygenated compounds increase the rate of Reaction B. This effect of $\mathrm{H}_{2} \mathrm{O}$ was unexpected because $\mathrm{H}_{2} \mathrm{O}$ is not a component of Reaction $\mathrm{B}$. The $\beta$ and $\gamma$ values for Reaction $\mathrm{C}$ indicate that increasing $\mathrm{CO}_{2}$ concentrations drive Reaction $\mathrm{C}$ forward at higher rates, while increasing concentrations of $\mathrm{H}_{2} \mathrm{O}$ drive the reaction in the reverse direction. The positive effect of $\mathrm{H}_{2} \mathrm{O}$ on Reaction B may be explained by the fact that $\mathrm{H}_{2} \mathrm{O}$, by driving Reaction $\mathrm{C}$ in the reverse direction, increases the concentration of $\mathrm{CO}_{2}-$ a reactant in Reaction $\mathrm{B}-$ and decreases the concentration of $\mathrm{CO}-\mathrm{a}$ product in Reaction B - thereby creating equilibrium driving forces that push Reaction B forward.

\section{Conversion and Hydrogen Recovery}

Three-dimensional plots of total methane conversion, total $\mathrm{H}_{2}$ recovery from methane, percentage of recovered $\mathrm{H}_{2}$ converted to $\mathrm{H}_{2} \mathrm{O}$, and total $\mathrm{CO}_{2}$ conversion versus $\mathrm{H}_{2} \mathrm{O}$ and $\mathrm{CO}_{2}$ mole fractions were constructed for analysis. For brevity, only the total conversion of $\mathrm{CO}_{2}$ is shown in Figure 5. The fit coefficients and corresponding statistical parameters for all fits are provided in Table 3.

The five fit coefficients given in Table 3 describe the fit surface with the relationship:

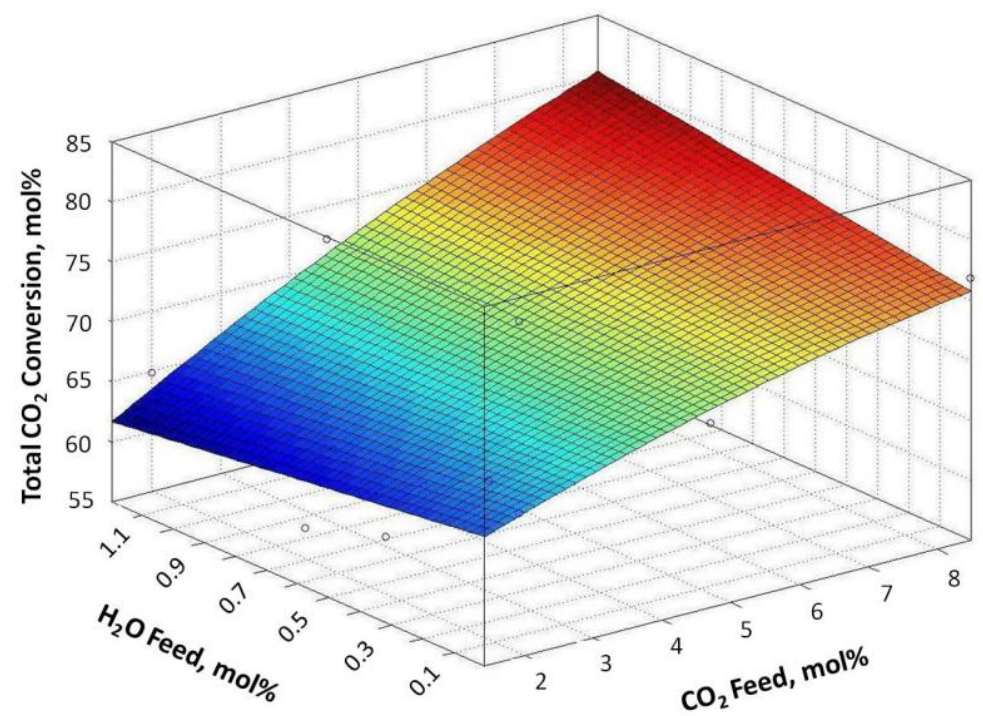

Figure 5. Total conversion of $\mathrm{CO}_{2}(\%)$ as a function of $\mathrm{CO}_{2}$ and $\mathrm{H}_{2} \mathrm{O}$ total feed mole fractions (\%).

$$
\text { Derived parameter }=\delta+\varepsilon^{*} \mathrm{y}_{\%, \mathrm{CO} 2}+\zeta^{*} \mathrm{y}_{\%, \mathrm{H} 2 \mathrm{O}}+\theta^{*}\left(\mathrm{y}_{\%, \mathrm{CO} 2}\right)^{2}+\kappa^{*} \mathrm{y}_{\%, \mathrm{CO} 2} * \mathrm{y}_{\%, \mathrm{H} 2 \mathrm{O}}
$$

Table 3. Fit coefficients and coefficients of determination for

\begin{tabular}{|c|c|c|c|c|c|c|c|}
\hline Dependent variable & $\delta$ & $\bar{\varepsilon}$ & $\zeta$ & $\theta$ & $\kappa$ & rsquare & adjrsquare \\
\hline$\chi_{\mathrm{CH} 4 \text {,total }}$ & 76.219 & 0.365 & 1.195 & 0 & 0 & 0.583 & 0.518 \\
\hline$\chi_{\mathrm{CH} 4-\mathrm{C} 2 \mathrm{H} 2}$ & 78.250 & -2.807 & -1.566 & 0 & 0 & 0.985 & 0.983 \\
\hline$\chi_{\mathrm{CH} 4-\mathrm{CO}}$ & -2.031 & 3.172 & 2.761 & 0 & 0 & 0.989 & 0.988 \\
\hline $\mathbf{T}_{\mathrm{H} 2: \mathrm{CH} 4 \text {,total }}$ & 56.656 & 1.067 & 1.587 & 0 & 0 & 0.928 & 0.916 \\
\hline$\chi_{\mathrm{H} 2(\mathrm{rec})-\mathrm{H} 2 \mathrm{O}}$ & 0.606 & 0.743 & -2.281 & 0 & 0 & 0.925 & 0.910 \\
\hline$\chi_{\mathrm{CO} 2, \text { total }}$ & 62.808 & 2.259 & -4.909 & -0.086 & 1.030 & 0.873 & 0.827 \\
\hline
\end{tabular}
conversion and recovery fits.
The $R^{2}$ values for total methane conversion are much lower than desirable. This is a result of the fact that the variation in the total methane conversion across all trials was relatively small (75.6-80.2\%), meaning that the variation in data points due to measurement error was large in comparison to the total variation. According to the low $\mathrm{R}^{2}$ value, the model equation for total methane conversion does not account well for 
variations in the methane conversion. However, the largest magnitude of any residual (difference between predicted and measured values of $\chi_{\mathrm{CH}_{4} \text {,toal }}$ ) was only $1.83 \%$, and $\chi_{\mathrm{CH}_{4}-\mathrm{C}_{2} \mathrm{H}_{2}}$ and $\chi_{\mathrm{CH}_{4}-\mathrm{CO}}$ were fit with relationships having high $\mathrm{R}^{2}$ values. No relationship with lower values of adjusted $\mathrm{R}^{2}$ could be found.

\section{Efficiency, Selectivity, and Yield}

Each of the calculated efficiency, selectivity, and yield parameters was plotted and fit with functions of the $\mathrm{CO}_{2}$ and $\mathrm{H}_{2} \mathrm{O}$ feed stream mole fractions using MATLAB's Surface Fitting Toolbox as in the previous sections. The most interesting plots, shown in Figure 6-Figure 9, were from the selectivity of $\mathrm{C}_{2} \mathrm{H}_{2}$ over $\mathrm{CO}$ and of $\mathrm{H}_{2}$ over water as well as the yield of $\mathrm{C}_{2} \mathrm{H}_{2}$ and $\mathrm{H}_{2}$. Fit coefficients with corresponding statistical parameters for all reactions and components are given in Table 4.

The five fit coefficients given in Table 4 describe the fit surface with the relationship:

$$
\text { Derived parameter }=\lambda+\mu^{*} \mathrm{y}_{\%, \mathrm{CO} 2}+v^{*} \mathrm{y}_{\%, \mathrm{H} 2 \mathrm{O}}+\xi^{*}\left(\mathrm{y}_{\%, \mathrm{CO} 2}\right)^{2}+\rho^{*} \mathrm{y}_{\%, \mathrm{CO} 2} \mathrm{y}_{\%, \mathrm{H} 2 \mathrm{O}}+\sigma^{*} \mathrm{y}_{\%, \mathrm{CO} 2}{ }^{\wedge} \varphi
$$

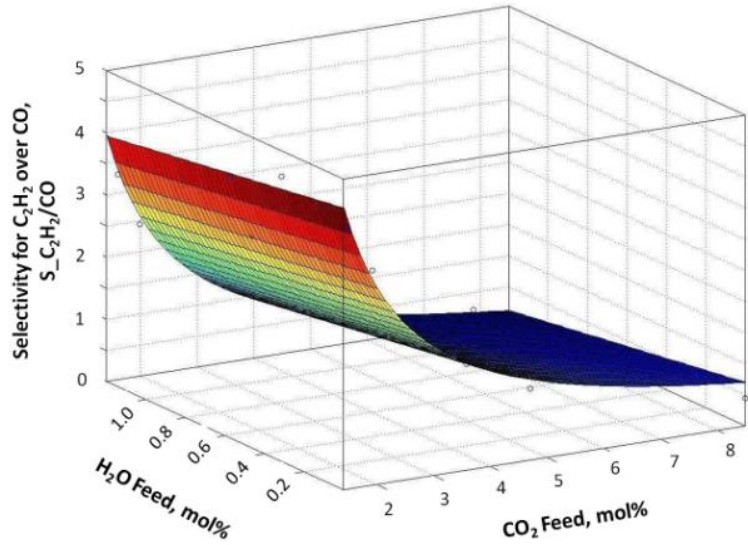

Figure 6. Selectivity for acetylene over carbon monoxide $\left(\mathrm{S}_{\mathrm{C}_{2} \mathrm{H}_{2} / \mathrm{CO}}\right)$ as a function of $\mathrm{CO}_{2}$ and $\mathrm{H}_{2} \mathrm{O}$ total feed mole fractions $(\%)$.

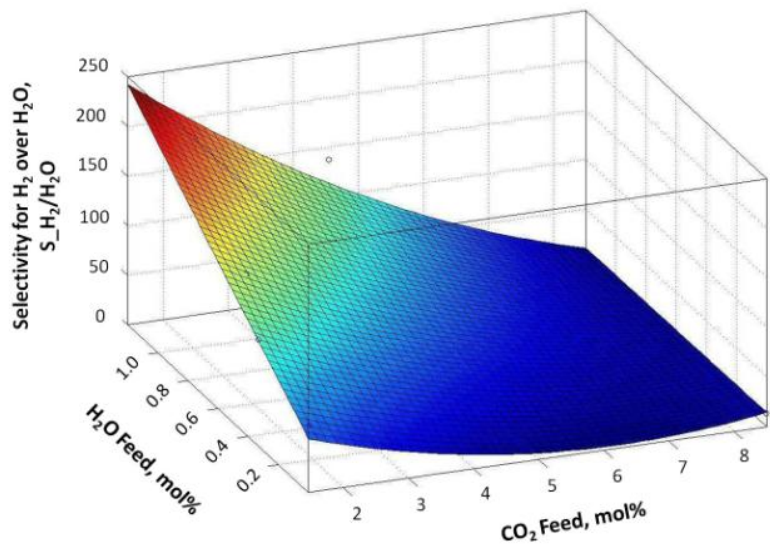

Figure 7. Selectivity for hydrogen over water $\left(\mathrm{S}_{-} \mathrm{H}_{2} / \mathrm{H}_{2} \mathrm{O}\right.$ ) as a function of $\mathrm{CO}_{2}$ and $\mathrm{H}_{2} \mathrm{O}$ total feed mole fractions $(\%)$.

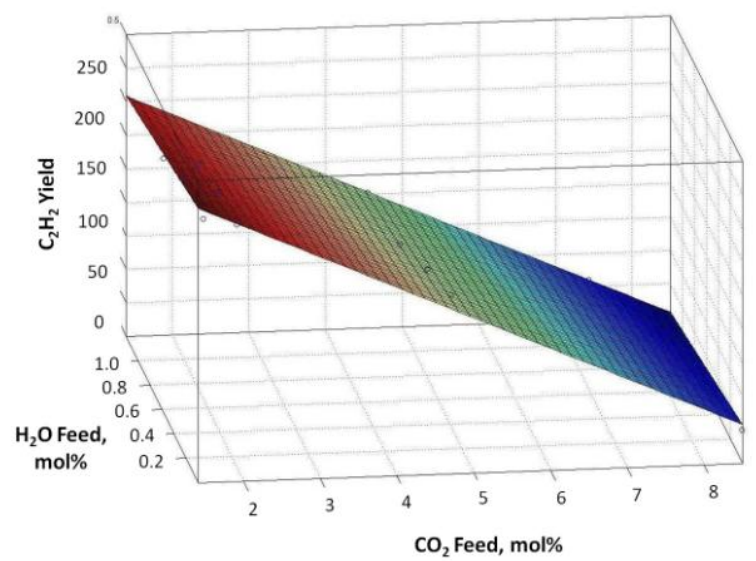

Figure 8. Acetylene yield $\left(\mathrm{Y}_{\mathrm{C}_{2} \mathrm{H}_{2}}\right)$ as a function of $\mathrm{CO}_{2}$ and $\mathrm{H}_{2} \mathrm{O}$ total feed mole fractions $(\%)$.

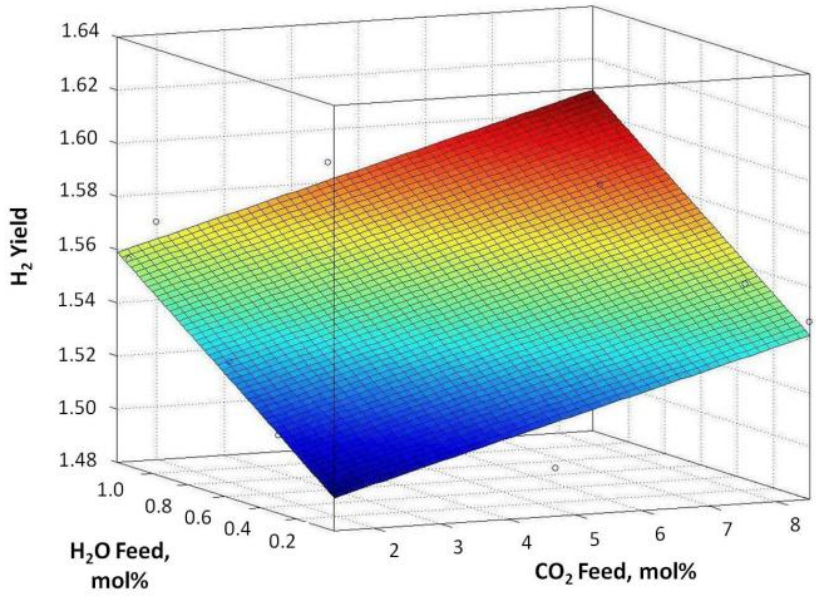

Figure 9. Hydrogen yield $\left(\mathrm{Y}_{-} \mathrm{H}_{2}\right)$ as a function of $\mathrm{CO}_{2}$ and $\mathrm{H}_{2} \mathrm{O}$ total feed mole fractions $(\%)$. 
Table 4. Fit coefficients and coefficients of determination for the efficiency, selectivity, and yield surface fit functions.

\begin{tabular}{|c|c|c|c|c|c|c|c|c|c|}
\hline $\begin{array}{c}\text { Dependent } \\
\text { variable }\end{array}$ & $\boldsymbol{\lambda}$ & $\boldsymbol{\mu}$ & $\mathbf{v}$ & $\boldsymbol{\xi}$ & $\boldsymbol{\rho}$ & $\boldsymbol{\sigma}$ & $\boldsymbol{\phi}$ & rsquare & adjrsquare \\
\hline $\boldsymbol{\eta}_{\mathbf{A}(\%)}$ & 3.140 & -0.104 & -0.015 & 0 & 0 & 0 & 0 & 0.982 & 0.979 \\
\hline $\boldsymbol{\eta}_{\mathbf{B}(\%)}$ & -0.123 & 0.174 & 0.159 & 0 & 0 & 0 & 0 & 0.990 & 0.989 \\
\hline $\boldsymbol{\eta}_{\mathbf{C}(\%)}$ & 0.003 & 0.009 & -0.027 & 0 & 0 & 0 & 0 & 0.958 & 0.951 \\
\hline $\boldsymbol{\eta}_{\text {Overall (\%) }}$ & 3.020 & 0.080 & 0.117 & 0 & 0 & 0 & 0 & 0.975 & 0.971 \\
\hline $\mathbf{S}_{\mathbf{C 2 H} / \mathbf{C O}}$ & 0 & 0 & -0.487 & 0 & 0 & 6.449 & -1.035 & 0.984 & 0.981 \\
\hline $\mathbf{S}_{\mathbf{H} 2 / \mathrm{H} 20}$ & 90.200 & -27.900 & 190.200 & 2.235 & -22.720 & 0 & 0 & 0.896 & 0.844 \\
\hline $\mathbf{Y}_{\mathbf{C 2 H} 2}$ & 0.511 & -0.020 & -0.017 & 0 & 0 & 0 & 0 & 0.991 & 0.990 \\
\hline $\mathbf{Y}_{\mathbf{H} 2}$ & 1.483 & 0.007 & 0.056 & 0 & 0 & 0 & 0 & 0.838 & 0.813 \\
\hline $\mathbf{Y}_{\mathbf{C O}}$ & -0.039 & 0.092 & 0.029 & 0 & 0 & 0 & 0 & 0.997 & 0.997 \\
\hline $\mathbf{Y}_{\mathbf{H} 20}$ & 0.006 & 0.013 & -0.039 & 0 & 0 & 0 & 0 & 0.957 & 0.951 \\
\hline
\end{tabular}

Overall reaction energy efficiency increases slightly with $\mathrm{CO}_{2}$ and $\mathrm{H}_{2} \mathrm{O}$, but this is at the expense of decreasing the rate of the desired Reaction A. Reaction efficiencies are low, in the neighborhood of $3 \%$ for the overall process. According to this regression analysis, the reaction efficiency with no $\mathrm{CO}_{2}$ or $\mathrm{H}_{2} \mathrm{O}$ present should be between 3.02 and

$3.14 \%$. Prior testing of the PPA with the same methane and hydrogen feed rates, but without the oxygenated compounds, resulted in a reaction efficiency of $3.32 \%$ when calculated by this method". In the "Reaction Rates" section, it was shown that increasing $\mathrm{CO}_{2}$ concentrations cause the rate of Reaction A to decrease, while simultaneously causing the rates of Reactions $\mathrm{B}$ and $\mathrm{C}$ to increase. As a result, the selectivity for acetylene in preference to carbon monoxide as the product of methane conversion decreases rapidly with increasing $\mathrm{CO}_{2}$ in the tested ranges. Correspondingly, the acetylene and carbon monoxide yields decrease and increase, respectively, due to increasing $\mathrm{CO}_{2}$ concentration. Water also causes a decrease in selectivity for acetylene, but the effect is relatively modest within the range of water vapor concentrations attained in this study.

Selectivity for hydrogen over water as the ultimate form of the hydrogen recovered from methane $\left(\mathrm{S}_{\mathrm{H} 2 / \mathrm{H} 2 \mathrm{O}}\right)$ is greatest at low $\mathrm{CO}_{2}$ concentrations and high $\mathrm{H}_{2} \mathrm{O}$ concentrations.

\section{B. Series B Results and Discussion}

Series B test points were designed to explore PPA performance from SDU product streams potentially produced from nominal SDU feed compositions. Results and Discussion of PPA performance under these conditions are provided below.

\section{Reaction Rates}

Rates of the three model reactions for each trial in Series B were plotted against the ratio of hydrogen to carbon dioxide in the $S D U$ inlet stream ("SDU ratio"). Values of the fit terms, as well as coefficients of determination for the fits, are given in Table 5.

For Reactions A and B, the best fit is a quadratic polynomial of the form:

$$
\text { rate }=a^{*} \text { SDU ratio }{ }^{2}+b^{*} \text { SDU ratio }+c
$$

The best fit for Reaction $\mathrm{C}$ is a power expression of the form:

$$
\text { rate }=d^{*} \operatorname{SDU} \text { ratio }^{\mathrm{f}}+\mathrm{g}
$$

Table 5. Fit parameters and coefficients of determination for reaction rate fits - Series $B$.

\begin{tabular}{|c|c|c|c|c|c|}
\hline Reaction & a & b & c & rsquare & adjusted rsquare \\
\hline A & -7.746 & 67.610 & -69.960 & 0.942 & 0.883 \\
\hline B & 3.886 & -37.440 & 99.000 & 0.920 & 0.839 \\
\hline & & & & & \\
\hline & d & $\mathbf{f}$ & $\mathbf{g}$ & rsquare & adj rsquare \\
\hline C & 8690 & -4.674 & -14.940 & 0.989 & 0.979 \\
\hline
\end{tabular}

The rate of Reaction A appears to peak at an SDU feed ratio of approximately 4.4 moles hydrogen to 1 mole carbon dioxide. This is likely the case because at lower ratios, a higher concentration of unreacted $\mathrm{CO}_{2}$ is present in the SDU product, making Reaction B more favorable and decreasing acetylene selectivity, while at higher SDU inlet ratios, the methane concentration is decreased by the excess hydrogen in the SDU product stream. This decreases the probability of the methane ionization products contacting one another and recombining as acetylene. Since the total amount of methane and hydrogen in the PPA reactor was constant, the effect is a function of the distribution of the hydrogen flow between 
the methane feed stream and the sweep streams. In other words, the rate of Reaction A is likely greatest when all hydrogen is fed through the sweep ports and none is mixed in the methane stream. This is in agreement with previous testing. ${ }^{5}$

The rate of Reaction B appears to be at a minimum when the SDU feed ratio is approximately 4.8. At lower SDU feed ratios, the high concentration of unreacted $\mathrm{CO}_{2}$ provides a driving force which pushes the Reaction $\mathrm{B}$ equilibrium to the right. Likewise, at low SDU feed ratios, Reaction $\mathrm{C}$ proceeds rapidly due to the excess $\mathrm{CO}_{2}$. At higher SDU feed ratios, the total main port feed rate to the PPA was increased in order to maintain the 200 sccm flow rate of methane despite the lower methane fraction. As a result, the sweep hydrogen flow rate was decreased in order to maintain total hydrogen flow rate at $800 \mathrm{sccm}$. The main stream is saturated or nearly saturated with water vapor, while the sweep streams are dry. Thus, higher primary port flow rates and lower $\mathrm{H}_{2}$ sweep port flow rates lead to greater overall water concentration. This provides the impetus for Reaction $\mathrm{C}$ to proceed in the reverse direction, and the $\mathrm{CO}_{2}$ thereby produced pushes Reaction B forward. Since Reactions B and C do not represent the true reaction pathway, it should be understood simply that the higher water concentration promotes the consumption of water and methane to form carbon monoxide and hydrogen.

\section{Conversion and Hydrogen Recovery}

Conversion of $\mathrm{CO}_{2}$ and recovery of hydrogen were calculated for all test points in Series B. Figure 10 shows the data points and best fit curve for total methane conversion versus SDU feed ratio. Fits and data points for total methane conversion percent, percent of methane converted to acetylene, and methane conversion were calculated as a function of hydrogen mole fraction in the primary PPA feed stream and compared to prior testing with no oxygenated compounds present. ${ }^{5}$ These fits were found to be highly imprecise but indicated that the overall methane conversion in current and previous testing decreases above $50 \%$ hydrogen (corresponding to SDU feed ratios of at least $5: 1$ ) as a result of the decreased methane concentration. Additionally, the conversion of methane to acetylene was shown to be lower at all points in current testing as compared to previous results, and at higher mole fractions of hydrogen in the internal stream,

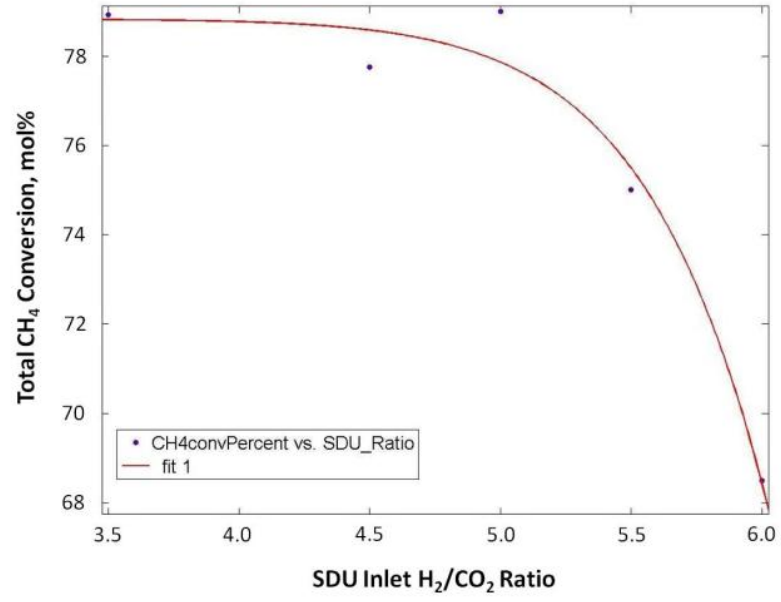

Figure 10. Total percentage of feed methane converted in PPA as a function of SDU inlet hydrogen-to-methane fraction.

even the overall methane conversion appeared lower for the OCT data, as there was no unreacted $\mathrm{CO}_{2}$ to react in Reaction B.

Data points and the best fit line for hydrogen recovery from methane were analyzed as functions of the SDU feed ratio. Table 6 provides the values of the parameters for the fits along with the corresponding coefficients of determination where the parameters $\mathrm{a}, \mathrm{b}$, and $\mathrm{c}$ describe the fit curve according to the power expression:

$$
\text { rate }=\mathrm{k}^{*} \mathrm{SDU} \text { ratio }^{1}+\mathrm{m}
$$

Methane conversion was shown to decrease sharply at higher SDU feed ratios because, as discussed in the previous section, the decrease in the rate of Reaction A is much greater than the increase in the rate of Reaction B. For the same reason, hydrogen recovery drops steeply at higher SDU feed ratios. The highest measured percent methane conversion and hydrogen recovery were found at the minimum SDU feed ratio of 3.5 hydrogen to carbon dioxide.

It is difficult to define $\mathrm{CO}_{2}$ conversion for Trials 21-24 since essentially no $\mathrm{CO}_{2}$ was fed to the PPA reactor. Thus, $\mathrm{CO}_{2}$ conversion was not included in the Series B analysis.

Table 6. Fit parameters and coefficients of determination for methane conversion and hydrogen recovery - Series $B$.

\begin{tabular}{|c|c|c|c|c|c|}
\hline Dependent Variable & $\mathbf{k}$ & $\mathbf{I}$ & $\mathbf{m}$ & rsquare & adjusted rsquare \\
\hline $\boldsymbol{\chi}_{\mathrm{CH} 4, \text { total }}$ & $-7.07 \times 10^{-10}$ & 13.077 & 78.820 & 0.971 & 0.942 \\
\hline $\boldsymbol{\tau}_{\mathrm{H} 2 \text {-CH4,total }}$ & $-1.10 \times 10^{-8}$ & 11.340 & 60.650 & 0.959 & 0.917 \\
\hline
\end{tabular}




\section{Efficiency, Selectivity, and Yield}

All efficiency, selectivity, and yield parameters were calculated. A selection of these was plotted and fit with functions of the SDU feed ratio. Plots of these data points and fit functions are shown in Figure 13 - Figure 11, and all fit coefficients with corresponding statistical parameters are given in Table 7 where $a, b$, and c are coefficients of the quadratic fit as in the Reaction Rates section. Efficiencies of Reactions A and B mirror the rates of those reactions previously discussed. Overall reaction efficiencies for Series B were comparable to those of Series A

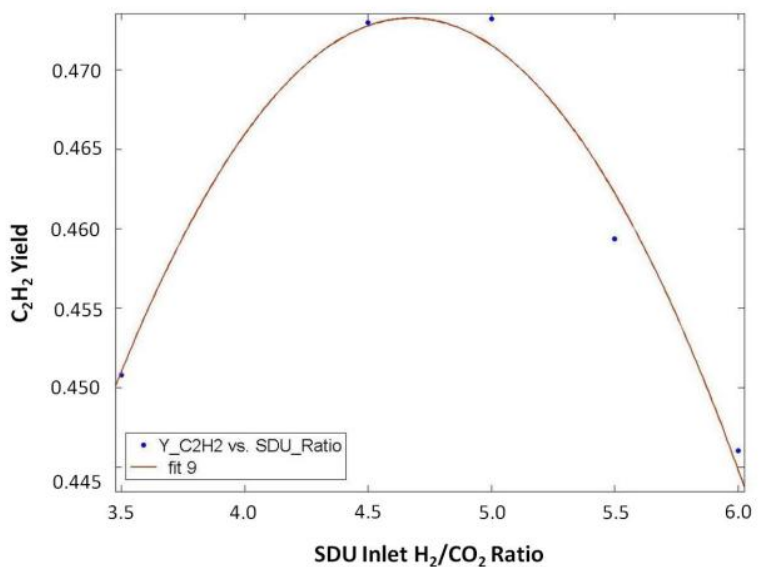

Figure 13. Acetylene yield $\left(\mathrm{Y}_{-} \mathrm{C}_{2} \mathrm{H}_{2}\right)$ as a function of SDU feed ratio.

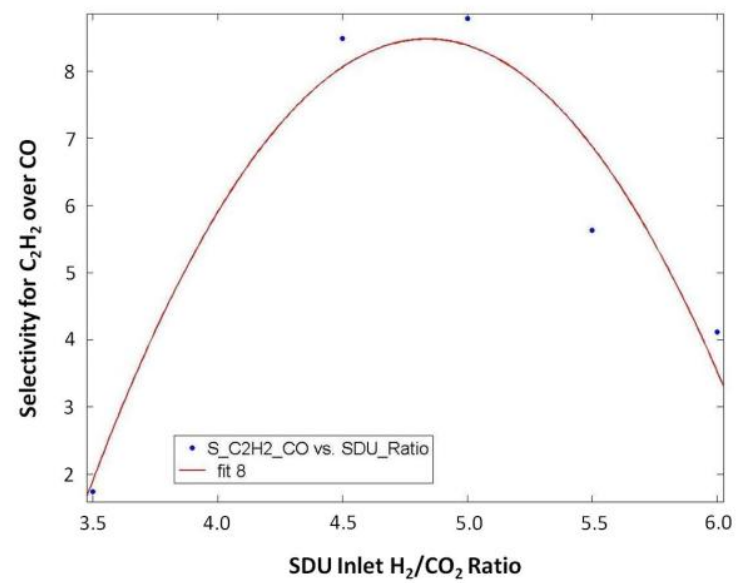

Figure 12. Selectivity for acetylene over carbon monoxide $\left(\mathrm{S}_{-} \mathrm{C}_{2} \mathrm{H}_{2} / \mathrm{CO}\right)$ as the product of methane conversion as a function of SDU feed ratio.

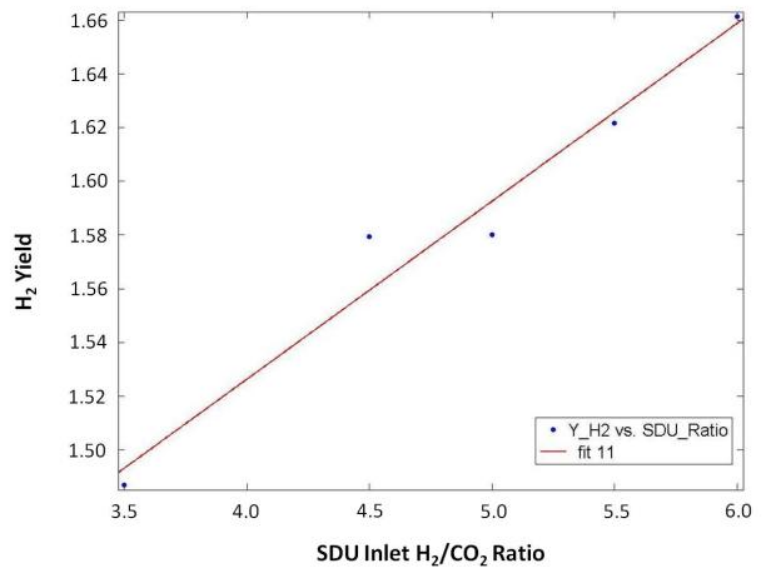

Figure 14. Hydrogen yield $\left(\mathrm{Y}_{-} \mathrm{H}_{2}\right)$ as a function of SDU feed ratio.

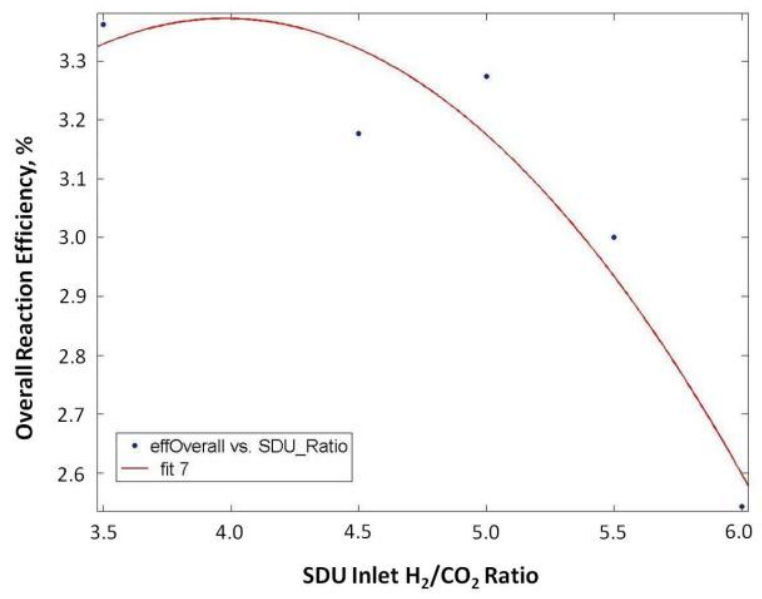

Figure 11. Overall PPA reaction efficiency as a function of SDU feed ratio.

Table 7. Efficiency, selectivity, and yield fit coefficients with corresponding coefficients of determination.

\begin{tabular}{|c|c|c|c|c|c|}
\hline Dependent variable & $\mathbf{a}$ & $\mathbf{b}$ & $\mathbf{c}$ & rsquare & adjrsquare \\
\hline $\boldsymbol{\eta}_{\mathbf{A}(\%)}$ & -0.311 & 2.711 & -2.805 & 0.942 & 0.883 \\
\hline $\boldsymbol{\eta}_{\mathbf{B}(\%)}$ & 0.102 & -0.983 & 2.599 & 0.920 & 0.839 \\
\hline $\boldsymbol{\eta}_{\text {Overall (\%) }}$ & -0.189 & 1.506 & 0.376 & 0.907 & 0.813 \\
\hline $\mathbf{S}_{\mathbf{C 2 H} 2 / \mathrm{CO}}$ & -3.669 & 35.500 & -77.410 & 0.937 & 0.873 \\
\hline $\mathbf{Y}_{\mathbf{C 2 H} 2}$ & -0.016 & 0.151 & 0.121 & 0.980 & 0.959 \\
\hline $\mathbf{Y}_{\mathbf{H} 2}$ & 0.000 & 0.066 & 1.261 & 0.963 & 0.951 \\
\hline $\mathbf{Y}_{\mathbf{C O}}$ & 0.084 & -0.851 & 2.204 & 0.969 & 0.938 \\
\hline
\end{tabular}


except at SDU feed ratios of 5.5 and above, at which point overall efficiency was significantly lower for Series B. Overall efficiency appears to be at a maximum at an SDU feed ratio of approximately 4.0. Acetylene yield has an apparent maximum near an SDU ratio of 4.7, while carbon monoxide yield has an apparent minimum near 5.0. Accordingly, selectivity for acetylene versus carbon monoxide as the product of methane conversion peaks at approximately 4.8 moles of hydrogen per mole of carbon dioxide in the SDU feed stream. Hydrogen yield seems to increase linearly with SDU feed ratio. The greatest yield of hydrogen was observed at the highest SDU feed ratio tested.

\section{Summary}

A summary of the results of the PPA Oxygenated Compounds Test is provided in Table 8.

Table 8. Summary of PPA OCT results.

\begin{tabular}{|c|c|}
\hline Test Series & Key Findings \\
\hline \multirow[t]{3}{*}{$\mathrm{A}$} & $\begin{array}{l}\text { Both PPA methane conversion and hydrogen recovery increase with increasing } \mathrm{CO}_{2} \text { and } \\
\qquad \mathrm{H}_{2} \mathrm{O} \text { concentrations. }\end{array}$ \\
\hline & $\mathrm{CO}_{2}$ and $\mathrm{H}_{2} \mathrm{O}$ cause lower acetylene production and higher $\mathrm{CO}$ production rates. \\
\hline & $\begin{array}{l}\text { Overall energy efficiency increases with increasing } \mathrm{CO}_{2} \text { and } \mathrm{H}_{2} \mathrm{O} \text { feed concentrations, } \\
\text { but less input power is utilized for the desired production of acetylene. }\end{array}$ \\
\hline \multirow[t]{4}{*}{ B } & $\begin{array}{c}\text { With no } \mathrm{CO}_{2} \text { or } \mathrm{H}_{2} \mathrm{O} \text { removal (besides condensation to a room-temperature dew point) } \\
\text { between the Sabatier and Plasma Pyrolysis... }\end{array}$ \\
\hline & ... acetylene production rate is maximized by SDU feed ratios $\left(\mathrm{H}_{2}: \mathrm{CO}_{2}\right)$ of near 4.0. \\
\hline & ...energy efficiency of acetylene production is maximized by SDU feed ratios near 4.0. \\
\hline & $\begin{array}{l}\text {... selectivity for acetylene over CO as the product of methane conversion is maximized } \\
\text { near SDU feed ratios of } 4.8 .\end{array}$ \\
\hline General & $\begin{array}{l}\text { The presence of } \mathrm{CO}_{2} \text { and } \mathrm{H}_{2} \mathrm{O} \text { in the PPA feed stream in the tested domain does not lead } \\
\text { to the production of measureable concentrations of molecular oxygen. }\end{array}$ \\
\hline
\end{tabular}

\section{Conclusion}

The only reaction products observed in the PPA outlet stream were acetylene and carbon monoxide. The absence of oxygen production is an important observation for the PPA development effort since the potential presence of oxygen in a gas flow containing highly combustible compounds (hydrogen, methane, acetylene) would necessitate the recognition of added risks and the application of further safety measures which would handicap microwave plasma methane pyrolysis systems in trade studies against other technologies.

It was shown that, in the tested domain, carbon dioxide $\left(\mathrm{CO}_{2}\right)$ in the feed stream to the PPA increases the overall methane conversion, hydrogen recovery, and energy efficiency, but decreases the acetylene production as selectivity for acetylene $\left(\mathrm{C}_{2} \mathrm{H}_{2}\right)$ over carbon monoxide $(\mathrm{CO})$ decreases sharply. In most cases, water exhibits the same effects to a somewhat lesser magnitude.

This investigation has opened the possibility of removing the $\mathrm{CO}_{2}$ and $\mathrm{H}_{2} \mathrm{O}$ sorbent bed from the Sabatier/pyrolysis system, thereby decreasing the power and mass requirements for the hardware. Process comparison studies must be conducted to determine whether such a system would be advantageous for a given mission.

Because life-support system utility will depend on the ability to recovery oxygen, and most CDRe technologies require hydrogen as the reducing agent, hydrogen recovery technology must be advanced. To this end, future work with the PPA will be focused on acetylene separation - to allow recycle of unreacted hydrogen and methane - as well as microwave plasma reactor optimization.

\section{Acknowledgments}

The authors thank UMPQUA Research Company for their previous and continued efforts toward the development of methane pyrolysis hardware; Tom Williams for the development of much of the data acquisition and control software essential to testing of the SDU and PPA; Kenny Bodkin for technician support; and Gena Dalton and Joseph Scott for technical support with gas chromatography. 


\section{References}

${ }^{1}$ Atwater, J.E., Wheeler, R.R.,Jr., Hadley, N.M., Dahl, R.W., Carrasquillo, R.L., "Development and Testing of a Prototype Microwave Plasma Reactor for Hydrogen Recovery from Sabatier Waste Methane," $39^{\text {th }}$ International Conference on Environmental Systems, SAE International, SAE 2009-01-2467, Savannah, Georgia, 2009.

${ }^{2}$ Abney, M.B., Miller, L.A., Williams, T., "Sabatier Reactor System Integration with Microwave Plasma Methane Pyrolysis Post-Processor for Closed-Loop Hydrogen Recovery, “ $40^{\text {th }}$ International Conference on Environmental Systems, AIAA-20106474, Barcelona, Spain, 2010.

${ }^{3}$ Fridman, A., "Plasma Chemistry," Cambridge University Press, New York, New York, 2008.

${ }^{4}$ Liley, P.E., Thompson, G.H., Friend, D.G., Daubert, T.E., Buck, E., Perry's Chemical Engineering Handbook, 7th ed., McGraw-Hill, 1997, pp 2-199.

${ }^{5}$ Abney, M.B., Miller, L.A., "Sabatier Development Unit and Plasma Pyrolyis Assembly Integrated Testing Report," NASA Marshall Space Flight Center, ES62, Huntsville, AL, 2010. 